\title{
Safety study, anti-inflammatory and antioxidant action of drug caramel with polyhexamethylene guanidine phosphate
}

\author{
Anton V. Kurinnyi ${ }^{1}{ }^{*}$, Igor F. Belenichev ${ }^{2}$, Vitalii V. Hladyshev ${ }^{1}$
}

\begin{abstract}
${ }^{1}$ Department Drug Technology of Zaporozhye State Medical University, Ukraine ${ }^{2}$ Department of Pharmacology and Medical Recipes of Zaporozhye State Medical University, Ukraine
\end{abstract}

Received: 16 May 2016

Accepted: 04 July 2016

\section{*Correspondence to:}

Dr. Anton V. Kurinnyi,

Email: anton.kyrinnoy@ gmail.com

Copyright: (c) the author(s), publisher and licensee Medip Academy. This is an openaccess article distributed under the terms of the Creative Commons Attribution NonCommercial License, which permits unrestricted noncommercial use, distribution, and reproduction in any medium, provided the original work is properly cited.

\begin{abstract}
Background: Among the new antiseptic medicines, most meeting modern requirements in terms of treatment of microbial invasion are one of the leading positions occupied by the polymeric guanidine compound. Polyhexamethylene guanidine phosphate (PHMGP) has a wide spectrum of antimicrobial activity and practical absence of toxicity. We have developed a new dosage form caramel "Guamel"' with the active pharmaceutical ingredient.

Methods: on white rats of both sexes were studied parameters of acute toxicity and irritant dosage form caramel "Guamel", as well as anti-inflammatory and antioxidant effects.

Results: It was found that the PHMGP developed drug caramel does not have skin-resorptive and allergenic action. Study of acute toxicity on white rats showed harmlessness studied dosage form PHMGP. It was found that a single oral administration to laboratory animals in drug caramel maximum allowable amount and cutaneous application does not lead to death during a 48 hour period of observation, does not cause visible changes in the basic physiological processes and does not affect the function of vital organs. On carrageenan model of inflammation it proved that the drug caramel with PHMGP exhibits anti-inflammatory effect, such a superior drug-referent "Septolete". It is also found to have developed in preparation of antioxidant activity in the inhibition of oxidative protein modifications also significantly superior to the reference drug.

Conclusions: The developed dosage form caramel "Guamel" for external use of the safety performance meets the requirements for such drugs. The developed dosage form caramel "Guamel"' exhibits high anti-inflammatory and antioxidant activity, which is the force exceeds the reference value. All of this is experimental rationale for the industrial production of this dosage form caramel "Guamel"'.
\end{abstract}

Keywords: PHMGP, Dosage form caramel guamel, Acute toxicity, Irritating, Anti-inflammatory and antioxidant activity

\section{INTRODUCTION}

One of the most common and effective methods of treating wounds - a wound surface on application of various drugs for the purpose of cleansing and healing wounds. In modern pharmacology, the term "topical medication of wounds" is meant the use of medicaments in the form of solutions, ointments, sprays, gels, suspensions, and in ENT - in practice - in the form of drops and lozenges. The oral route of administration is the basis for many drugs. However, it has several disadvantages, among which: the unpleasant taste and odor; influence of the digestive enzymes and constituents of food on drug absorption, rate of absorption dependent on the content of the digestive tract etc. ${ }^{1-9}$

One way to overcome these disadvantages is to provide medicines based confectionery. This is especially true of drugs for infant and geriatric practice, as well as drugs with local action for the prevention and treatment of dental diseases; inflammation of the throat and pharynx, prevention of dental caries, to excite the appetite, increase the body's vital functions, prevention of cancer, eliminating odor and taste of drugs, etc. ${ }^{10}$ 
Currently, the global market of confectionery drugs filled not fully and completely at the expense of imports. And in this market segment is no domestic pharmaceuticals in the form of candy, which would at the same time had a pronounced anti-inflammatory activity, wound healing, antioxidant and analgesic properties.

Therefore, research on the creation and introduction in medical practice of new drugs based on the confectionery is of practical interest for the domestic medicine. ${ }^{10-11}$

Among the new antiseptic preparations, most meeting modern requirements in terms of treatment of microbial invasion are one of the leading positions occupied by the polymeric guanidine compound. Polyhexamethyleneguanidine phosphate (PHMGP) possesses a broad spectrum of antimicrobial activity and practical absence of toxicity. PHMGP serially produced by the original Ukrainian technology, and its cost is low, which makes the drug available for the Health of Ukraine and the general population.

Based on the above, the creation of new scientificallycompositions and dosage forms of new technology-based PHMGP antimicrobial action for the dental practice is relevant for the domestic pharmaceutical science.

\section{METHODS}

In part, manufactured by means of oral care "Guamel"' in the form of caramel includes PHMGP (0.1\%) concentrates extracts of Echinacea purpurea herb, chicory roots, pollen $(0.5 \%$ each) on the basis of caramel ( sugar, starch syrup caramel, citric acid).

The dosage form caramel "Guamel" produced by boiling caramel mass with subsequent molding in metal molds from the machine type "confection devilment" in training pharmacy drug technology department of Zaporozhye State Medical University.

The prepared dosage form is standardized in accordance with the specifications of Ukraine TU U 20.4202010741-077:2013 "Means oral care "Guamel"" on the following parameters: appearance, smell and taste, $\mathrm{pH}$ of $10 \%$ aqueous solution, mass fraction of water and volatile substances, disintegration time, the mass fraction of PHMGP, microbiological purity.

Pharmacological studies of drug caramel PGMGF made at the department of pharmacology of the Zaporozhye State Medical University. The volume of clinical trials determined according to the requirements of the order of the Ministry of Health of Ukraine №441 from 01.11.2001 "On approval of the pre-clinical study of medicinal products". The experimental part is made on nonlinear white rats of both sexes received from the nursery of the State Institution "institute of pharmacology and toxicology of the national academy of medical sciences of Ukraine". Animal sex distribution was not spent because of the uneven number of females and males. During the experiment, animals were kept under standard conditions at a temperature of $18-24{ }^{\circ} \mathrm{C}$, humidity 50 $60 \%$, natural light mode "day-night" at a constant food and drinking regime according to the rules of the content of the experimental animals, the European Union established by Directive 2010/63/ EU and the Ministry of education and science, youth and sports of Ukraine of 01.03.2012, the number 249. All procedures with animals were carried out according to international requirements "of the European Convention for the protection of vertebrate animals, which is used for experimental and other scientific purposes" (Strasbourg 1986), GLP and according to the guidelines of the State enterprise "Health Ministry of Ukraine State expert center".

Acute toxicity studies were performed on white rats, weighing 180-220g.

To determine the acute toxicity of each drug the animals were divided into three groups of 12 animals each. The animals were cut out areas of the skin on the back-the first $2 \times 2 \mathrm{~cm}$ group, respectively, the second $4 \times 4 \mathrm{~cm}$, the third- $8 \times 8 \mathrm{~cm}$ on the shaved areas of skin coated candies, pre-dissolved in the minimum amount of warm water, in amounts - $3.0 \mathrm{ml}, 6.0 \mathrm{ml}$ and $12.0 \mathrm{ml}$, respectively shaved skin area. Each volume of the drug was applied to six animals once. The animals were observed for 48 hours. During the entire period of observation was recorded the death of animals, as well as changes in the cardiovascular system, respiratory system, central nervous system, locomotor activity. The study was conducted allergenic effect in experiments on white rats - females weighing 140-160 g cut out the scalp in the area $4 \times 4 \mathrm{~cm}$ on a side surface of the animal body. ${ }^{12-16}$

This skin area was applied $1 \mathrm{ml}$ of the dissolved caramel, after which the animals were placed on a 4-hour individual cages to prevent licking the preparation. Administration is performed through drugs daily for 10 days (a total of 5 applications). Sensitization animals were detected at 5 days after the last drug application. For this purpose, an ear skin once applied $1 \mathrm{ml}$ of the preparation. The corresponding control groups of rats to similar plots were applied petrolatum or water. Local allergic reaction intensity was assessed at 6,12 and 24 hours. In case of no display studies the reaction is carried out up to 14 days. Accounting anaphylactic shock intensity was carried out in the indexes for Weigle. ${ }^{13}$

The study of local irritant effect on the mucous membrane was performed on white rats - females weighing 190-200 g, in accordance with the methodical instructions. ${ }^{12}$ The aqueous concentrate was applied drops of $5 \mathrm{mg}$ in the conjunctival sac of the right eye of animals and once pressed for 1 minute lacrimonasal channel near the inner corner of the eye. The left eye served as a control. Evaluation was performed after the damaging effect of 5, 15 minutes, 1 hour, and then daily for 5 days (score: no “_", mild “ \pm ”, moderate “++" and expressed by 
“+++"). ${ }^{12,14-16}$ Skin-resorptive effect was studied on white rats of both sexes weighing 200-230g. Thus it was formed a group 4 animals (10 in each). Animals were daily placed in individual cages and applied them to the whole area in the volume tailings preparations $2 \mathrm{ml}^{12,14-16}$

The corresponding control groups of rat tails lubricated with petroleum jelly or water. Exposure experiment corresponded to 5 hours a day. The whole experiment lasted for 30 days from Saturday and Sunday interruptions. After the 10-, 20- and 30-day applications were evaluated in animal orienting-investigative reaction in the "open field". To study the anti-inflammatory activity of drug caramel PHMGP experiments were performed on white rats of both sexes, weighing 180-200 g. In each series of experiments, the animals were divided into three groups of ten animals: 1) control, which entered flogogen (carrageenin); 2) experienced that on the background of the study flogogen assigns a concentrated solution of sugar candies "Guamel"; 3) reference, which on the background flogogen was administered of the concentrated solution lozenges "Septolete". Carrageenin in a $1 \%$ solution was administered once, subplantar rate of $0.1 \mathrm{ml}$ per animal. The test formulations were applied exterior to the foot investigated for three days before the injection and immediately after flogogen injection. Volume leg was measured at multiple time intervals. ${ }^{12,16-}$ 17 Antioxidant activity (AOA) of the test formulations were performed in vitro by the degree of inhibition of oxidative modification of protein. ${ }^{17}$ Method of estimation AOA inhibiting oxidative modification of the protein, called Fenton's reagent. The method is based on quantitative determination of amino acid residues oxidized protein by reaction with 2, 4dinitrophenylhydrazine (2, 4-DNPH), which are formed by Fenton's reagent initiation free radical oxidation invitro.

\section{Conducting research}

To $250 \mathrm{mg}$ of muscle homogenate was added $5 \mathrm{ml}$ of $0.5 \mathrm{M}$ phosphate buffer, $\mathrm{pH} 7.6\left(5^{\circ} \mathrm{C}\right)$ was stirred and centrifuged at $11000 \mathrm{~g}$ for 30 minutes (temperature $=5$ ${ }^{\circ} \mathrm{C}$ ). To $0.1 \mathrm{ml}$ of the prepared supertant (containing $1 \mathrm{mg}$ of protein) were added $0.1 \mathrm{ml}$ of the test substances $(\mathrm{C}=$ $10-6 \mathrm{M}$ ), $0.1 \mathrm{ml}$ of $2.8 \%$ iron (II) sulfate, $0.1 \mathrm{ml}$ of a $4 \%$ peroxide hydrogen. The volume of the incubation mixture was adjusted to $1 \mathrm{ml}$ of $0.5 \mathrm{M}$ phosphate buffer, $\mathrm{pH} 7.6$ and incubated at $37{ }^{\circ} \mathrm{C} 2$ hour. Then, $1 \mathrm{ml}$ of $25 \%$ trichloroacetic acid and centrifuged $30 \mathrm{~min}$ at 3000 rev/minutes $\left(15^{\circ} \mathrm{C}\right)$. To the residue was added $1 \mathrm{ml}$ of $2.2 \%$ 2, 4-dinitrophenyl hydrazine (prepared in $7 \%$ hydrochloric acid) and incubated for 1 hour at $37{ }^{\circ} \mathrm{C}$, centrifuged for 10 minute at $3000 \mathrm{rev} / \mathrm{minute}$. The precipitate was washed with $3 \mathrm{ml}$ of ethyl acetate, diluted in $3 \mathrm{ml} 50 \%$ urea solution, add 1 drop of $7 \%$ hydrochloric acid solution and diluted with distilled water 12 times. The prepared solution was measured at a wavelength of $274,363 \mathrm{~nm}$ and a reference solution - $0.5 \mathrm{M}$ phosphate buffer. In terms of the extinction determined number of aldehyde phenyl hydrazone (APH) and ketone phenyl hydrazine (KPH).

\section{Statistics}

Results of the study were calculated using standard statistical package licensed program "STATISTICA ${ }^{\circledR}$ for Windows 6.0" (StatSoftInc., №AXXR712D833214FAN5), as well as "SPSS 16.0”, "Microsoft Office Excell 2003". Normality of distribution was assessed by Shapiro-Wilk. Data are presented as mean values. The significance of differences between mean values was determined by Student criterion for a normal distribution. In the case of distribution other than normal, or the analysis of ordinal variables used test U Mann-Whitney. For comparison, the independent variables in more than two samples were performed analysis of variance (ANOVA) for a normal distribution or a Kruskal-Wallis test for distribution, different from the normal. For all types of analysis were considered statistically significant differences $\mathrm{P}<0.05$ $(95 \%)$.

\section{RESULTS}

\section{Toxicological studies}

Acute toxicity study. Studies have shown a single application of different doses of study medication did not cause the death of animals and significant changes in the cardiovascular system, respiratory system, central nervous system and locomotor activity (Table 1).

Table 1: Results of acute toxicity studies of drug caramel (as a solution) for cutaneous administration.

\begin{tabular}{|lll|}
\hline $\begin{array}{l}\text { The area of the body to } \\
\text { which the drug was } \\
\text { applied, cm }\end{array}$ & $\begin{array}{l}\text { The dose of } \\
\text { drug } \\
\text { applied, } m l\end{array}$ & $\begin{array}{l}\text { The } \\
\text { death of } \\
\text { animals }\end{array}$ \\
\hline $2 \times 2$ & 3,0 & $0 / 6$ \\
\hline $4 \times 4$ & 6,0 & $0 / 6$ \\
\hline $8 \times 8$ & 12,0 & $0 / 6$ \\
\hline
\end{tabular}

Table 2: Results of acute toxicity studies of drug when administered orally caramel.

$\begin{array}{ll}\text { Dose }(\mathrm{mg} / \mathrm{kg}) & \text { The death of animals } \\ 15000 & 0 / 6\end{array}$

Since for cutaneous application of study medication was no animal death, we deemed appropriate to examine the acute toxicity when orally administered to rats. ${ }^{12,14-16}$ For this candy dissolved in the minimum amount of warm water and administered orally using a metal atraumatic tip. In connection with non-toxic drugs in cutaneous application dose for oral administration should be as input for this type of animal. For rats, it is $15000 \mathrm{mg} / \mathrm{kg}{ }^{14}$ single injection of caramel, rats did not cause the death of animals after 48 hours. Thus, the dosage form in the form 
of hard candy refers to "substantially non-toxic substances" (Table 2). ${ }^{12,14,16}$

Research allergenic effect. Based on the principle of the method of the local intensity of the allergic reaction was evaluated at 6,12 and 24 hours. The reaction was not revealed. With this in mind, we have continued to study up to 14 days. All animals examined reaction to the resolution of the dose of candy was negative. This suggests that the dosage form in the form of a caramel candy, allergenic action has not (Table 3$).^{13}$

Table 3: Results of the study drug caramel allergenic properties (in solution) (by Weigle indices).

\begin{tabular}{|lllllll|}
\hline \multirow{2}{*}{ Animal groups } & \multicolumn{6}{c|}{ Non-animal } \\
\hline Control & 1 & 2 & 3 & 4 & 5 & 6 \\
\hline $\begin{array}{l}\text { Animals that received caramel } \\
\text { "Guamel"" }\end{array}$ & 0 & 0 & 0 & 0 & 0 & 0 \\
\hline
\end{tabular}

Notes:
- $\quad++++$ - shock fatalities;

- $\quad+++$ - severe shock (general convulsions, asphyxia, the animal loses the ability to stay on the feet, falls on his side, does not die);

- $\quad++$ - moderate shock (small seizures, expressed the phenomenon of bronchospasm);

- + - a weak shock (some anxiety, shortness of breath, scratching faces, involuntary urination, defecation, ruffled fur);

- 0 - shock is not developed, there are no signs of it.

Table 4: Results of the study locally irritating action aqueous concentrate dosage caramel.

\begin{tabular}{|lll|}
\hline $\begin{array}{l}\text { Positive } \\
\text { response }\end{array}$ & $\begin{array}{l}\text { Negative } \\
\text { response }\end{array}$ & $\begin{array}{l}\text { Nature of the } \\
\text { response }\end{array}$ \\
\hline $6 / 6$ & $5 / 6$ & \pm \\
\hline
\end{tabular}

Notes: The numerator - number of animals with the corresponding reaction, denominator - number of animals in the group.

Table 5: Anti-inflammatory activity caramel solution "Guamel" in carrageenan edema.

\begin{tabular}{|lllllll|}
\hline \multirow{2}{*}{ Groups of animals } & \multicolumn{7}{c|}{ Paw swelling (V mm) after a time, hour } \\
\hline Control & 0,5 & 1,0 & 2,0 & 6,0 & 12 & 24 \\
\hline Caramel & $0,30 \pm 0,04$ & $0,57 \pm 0,03$ & $0,66 \pm 0,03$ & $0,95 \pm 0,03$ & $0,94 \pm 0,03$ & $0,78 \pm 0,03$ \\
\hline Septolete & $0,30 \pm 0,05$ & $0,57 \pm 0,04$ & $0,61 \pm 0,05$ & $0,86 \pm 0,02$ & $0,78 \pm 0,02 *$ & $0,52 \pm 0,03 *+$ \\
\hline
\end{tabular}

Notes: $\mathrm{p}<0.05$ - significant differences from the control group; + /- $\mathrm{p}<0.05$ - significant differences from the group Septolete.

Table 6: The antioxidant activity of the test compounds $(1 \mathrm{mg} / \mathrm{ml})$ in vitro $(\mathrm{n}=5)$ inhibition of oxidative modification of protein $(\mathrm{M} \pm \mathrm{m})$.

\begin{tabular}{|c|c|c|c|c|}
\hline Experimental groups & APH, u.s./g & AOA, $\%$ & KPH, u.s./g & AOA, $\%$ \\
\hline Caramel & $5,8 \pm 0,03 *^{+}$ & 42,0 & $3,34 \pm 0,02 * \Delta+$ & 52,0 \\
\hline Septolete & $7,0 \pm 0,002 *$ & 30 & $4,87 \pm 0,01 *$ & 30,0 \\
\hline Intact & $1,07 \pm 0,002$ & - & $1,37 \pm 0,02$ & - \\
\hline Control & $9,95 \pm 0,07$ & - & $6,87 \pm 0,002$ & - \\
\hline
\end{tabular}

Notes: ${ }^{\Delta}-\mathrm{p}<0,05$ towards Intact; ${ }^{*}-\mathrm{p}<0,05$ versus control; $+-\mathrm{p}<0,05$ relative to the reference formulation

The study of local irritant effect. In the study of a possible irritating effect of topically-aqueous concentrate caramel drug was found weakly expressed reaction on the part of the mucous membrane of the eyes of rats, indicating the absence of irritative action in this formulation (Table 4).

Skin-resorptive action. In this test, there was no reported difference in terms of cardiac and respiratory. This test allowed us to make the assumption that the investigated formulation has no negative effect on the whole body of the animal.

\section{Pharmacological studies}

Study of anti-inflammatory action. As studies have shown, both formulations anti-inflammatory effect in the carrageenan model of inflammation (Table5).

The tested formulations exhibit the most pronounced effect in the period from 12 to 24 hours of carrageenan inflammation ( $p<0.05)$. Significant differences between the group of animals receiving drug solution and topically caramel group treated with the reference drug "Septolete" as pastilles solution prior to the observed 12 hours after administration of carrageenin.

Study on antioxidant activity of inhibition of oxidative modification of protein (OMP), induced by Fenton's 
reagent showed that lollipop "Guamel" exhibits the desired activity, and the reduction of indicators such as the APH and KPH superior "Septolete" (Table 6).

Oxidative modification of protein structures of organs and tissues in inflammatory conditions leads to the disturbance of metabolic processes, receptor desensitization, and mitochondrial pore formation and, in consequence, the initiation of apoptosis. One of the key mechanisms of action of many well-known antiinflammatory agents with antioxidant mechanism of action is their ability to inhibit the processes of OMP and accumulation of marker of carbonyl and carboxyl products - APH and KPH. Therefore, a promising direction is to provide anti-inflammatory dosage forms that inhibit processes OMP. Study on inhibition of AOA OMP, induced by Fenton's reagent showed that caramel "Guamel" exhibits the desired activity, and the reduction of indicators such as the APH and KPH superior "Septolete".

\section{DISCUSSION}

It was found that the PGMGF developed drug caramel does not have skin-resorptive and allergenic action13. Study of acute toxicity on white rats showed harmlessness studied dosage form PGMGF. ${ }^{16}$ It was found that a single oral administration to laboratory animals in drug caramel maximum allowable amount and cutaneous application does not lead to death during a 48 hour period of observation, does not cause visible changes in the basic physiological processes and does not affect the function of vital organs. ${ }^{14}$ On carrageenan model of inflammation It proved that the drug caramel with PGMGF exhibits anti-inflammatory effect, such a superior drug-referent "Septolete". It is also found to have developed in preparation of antioxidant activity in the inhibition of oxidative protein modifications also significantly superior to the reference drug. ${ }^{17}$

\section{CONCLUSION}

The developed dosage form caramel "Guamel" for external use of the safety performance meets the requirements for such drugs. The developed dosage form caramel "Guamel" exhibits high anti-inflammatory and antioxidant activity, which is the force, exceeds the reference value. All of this is experimental rationale for the industrial production of this dosage form caramel "Guamel".

\section{ACKNOWLEDGEMENTS}

The authors express their sincere gratitude to the rector ZSMU, Professor Yury M. Kolesnik for allowing authors to the scientific and technical base of Zaporozhye State Medical University and head of the training health center laboratory Zaporozhye State Medical University Professor Abramov V. Andrey for assistance in carrying out pharmacological studies.
Funding: No funding sources

Conflict of interest: None declared

Ethical approval: The study was approved by the Institutional Ethics Committee

\section{REFERENCES}

1. Pavlichko S. Principles of adjusting dosage forms of children's. Pharmaceutical Journal. 2000;5:47-51.

2. On approval of the classifier dosage forms. The Ministry of Health of Ukraine from number 235. Available at http://www.yurinfo.org.ua/doc/1685064/Pro-zatverdzhenniaKlasifikatora-likarskikh-form.

3. Magomedov G, Oleynikov A, Plotnikov I. Confectionery. Bulletin VGUIT. 2002;3:59-61.

4. Marshalkin G. Confectionery. Moscow, Kolos; 1994:272.

5. Sidorenko M, Skobelskaya Z, Kondakova I. Pat. 2182435 RU, MKI A23 G3/00. A process for preparing caramel. № 2182435, appl. 14/06/01; publ. 20.05.02, Bul. Number 14

6. Sidorenko M, Skobelskaya Z, Kondakova I. Effect of $\mathrm{pH}$ on the kinetics of caramel it wet during storage. Storage and processing of agricultural raw materials, 2000;8;23-5.

7. Dragilev A, Kondakov I, Masolova V. Technological instruction on production of caramel. All-Union Scientific Research Institute of the confectionery industry, Moscow. 1990:90.

8. Shterman S. Analysis and substantiation of technological indicators of the main raw material for the production of caramel. Dissertation of the candidate of pharmaceutical sciences, Moscow. 2002:155.

9. Randonus J, Bernard J, Janssen H. Effect of oligomeric and polymeric adiitives on glass transition, viscosity and crystallization of amorphous isomalt. Food research International. 2000;33:41-51.

10. Yakimov A. Substantiation of technology research and health care facilities based confectionery. Dissertation of the candidate of pharmaceutical sciences. Technology of medicines and industrial pharmacy, Kiev. 2001:19.

11. Sidorenko M. Development of new types of candy by modeling its structural and mechanical characteristics. Dissertation of the candidate of technical sciences, Moscow. 2003:306.

12. Stefanova A. Guidelines preclinical studies of drugs. Psychology, Avicenna. 2002:568.

13. Alexeyeva O. Guidelines on the assessment of the allergenic properties of pharmacological agents. Ed. Moscow, Medicine. 1988:19.

14. Kozhemyakin Y, Khromov A, Filonenko M, Sayretdinova T. Scientific and practical advice on keeping laboratory animals and work with him. Kyiv. 2002:155.

15. The issuance of permission for the use and introduction of drugs. Pharmacologically Journal. 1996;1:S12-20. 
16. Kukes V, Bulaev V, Kolkhir V. Guidelines for preclinical studies of new drugs developed from natural raw materials. Manual on experimental (preclinical) study of new pharmacological substances. Moscow, Russian Federation -Minzdrav. 2005:348s.
17. Belenichev I, Gubsky Y, Dunaev V. Methods for assessing antioxidant chemical substance when initiating free-radical processes in experiments in vitro. Guidelines. Kyiv: State Pharmacopoeia Center the Ministry of Health of Ukraine; 2002:26.

Cite this article as: Kurinnyi AV, Belenichev IF, Hladyshev VV. Safety study, anti-inflammatory and antioxidant action of drug caramel with polyhexamethylene guanidine phosphate. Int $\mathbf{J}$ Basic Clin Pharmacol 2016;5:1456-61. 